УДК 811.161 .1

DOI: $10.18384 / 2310-7278-2015-4-14-17$

\title{
Герасименко НА.
}

Московский государственный областной университет

\section{ОФОРМЛЕНИЕ СВЯЗИ МЕЖДУ ГЛАВНЫМИ ЧЛЕНАМИ БИСУБСТАНТИВНОГО ПРЕДЛОЖЕНИЯ}

Аннотация: Офрормление предикативной связи в структуре бисубстантивного предложения разнообразно и представляет собой грамматическую проблему. Главные члены предикативного ядра этого типа предложений выражены именами существительными, которые по многим категориальным признакам не обладают способностью приспосабливать свою форму к форме определяющего слова. В статье описываются разные способы выражения предикативной связи: собственно согласование и смысловое согласование. Бисубстантивные предложения с точки зрения связи между главными членами рассматриваются как согласованные, несогласованные и несогласуемые.

Ключевые слова: бисубстантивные предложения, предикативная связь, координация, согласование, собственно согласование, смысловое согласованные, согласованные, несогласованные и несогласуемые бисубстантивные предложения.

\section{N. Gerasimenko \\ Moscow State Regional University \\ THE DESIGN OF LINKS BETWEEN PRINCIPAL MEMBERS OF BISUBSTANTIVE SENTENCES}

Abstract. Making connections in the predicative structure of bisubstantive sentence is diverse and represents a grammatical problem. The principal members of the predictive core in sentences of this type are expressed by nouns that do not have the ability to adapt its form to the form of the defining word in many categorical attributes. The article describes different ways of the predicative connection expression: proper sequence and meaningful sequence. Bisubstantive sentences in terms of communication between the principal members are considered to be consistent, inconsistent and nonconcordial.

Keywords: bisubstantive sentences, predicative connection, coordination, sequence, proper sequence, meaningful sequence, conistent, inconsistent and nonconcordial bisubstantive sentences.

Интерес к проблемам грамматики в современной русистике становится все более активным, о чём свидетельствуют публикации последних лет [см.: 2, 3, 7]. Проблема грамматической

(c) Герасименко Н.А., 2015. связи сказуемого с подлежащим до сих пор решается неоднозначно. Грамматическая зависимость сказуемого от подлежащего реализуется как подчинительная связь, в то же время семантически в предложении преобладает 
сказуемое. Как известно, синтаксическая связь - это способ оформления синтаксических отношений: «Связь слов - это соединение слов, выражающее с помощью определённых средств смысловое отношение между этими словами» $[6$, с. 6.].

Для обозначения предикативных отношений используются разные термины. Термин координация относится к многозначным и понимается в науке неодинаково. Так, в зарубежной лингвистике координацией принято называть связь, оформляющую сочинительные отношения [4, с. 15-16]. При таком подходе не учитывается грамматическая зависимость сказуемого от подлежащего. Равноправными главные члены двусоставного предложения являются только по отношению к их роли в формировании структуры предложения. Близко к этому понимание координации как типа связи, выражающей предикативные отношения и заключающейся во взаимовлиянии главных членов предложения друг на друга: «в структуре двусоставного предложения предикативность (или сказуемость) представлена <... как отношение двух компонентов, направленных друг к другу и «приписываемых» друг другу, причём второй компонент является «высказыванием по отношению к первому» [1, с. 37]. Существует узкое понимание термина координация как взаимосогласование финитного глагола и личного местоимения [5, т. 2, с. 14]. Во всех случаях координация предполагает структурное равенство, взаимное уподобление.

На наш взгляд, традиционное употребление термина согласование по отношению к связи главных членов двусоставного предложения более адекватно отражает предикативные отношения как разновидность признаковых отношений. Предикативный признак, названный в сказуемом, приписывается предмету, обозначенному подлежащим. Связь согласование как один из видов подчинительной связи подчёркивает грамматическую зависимость сказуемого.

В «Русской грамматике» связь согласование определяется как «подчинительная связь, которая выражается уподоблением формы зависимого слова форме главенствующего слова в роде, числе и падеже, либо в числе и падеже, либо только в падеже» [5, c. 20]. Бисубстантивные предложения (БП) имеют в грамматическом ядре два существительных (или их синтаксические эквиваленты), которые соединены с помощью связки. Именно связка является выразителем и показателем грамматической связи сказуемого с подлежащим в этих предложениях: Сегодняшний обход пенсионеров был для Клумбы способом вновь укрепиться в своей правоте (О. Славникова); Одна половина была спальней: здесь щели законопатили тряпками и рваным полиэтиленом (А. Иванов); Со стороны они выглядели необычной парой (Е. Чижова).

В бисубстантивных предложениях реализуются разные виды согласования: собственно согласование и смысловое согласование.

Собственно согласование - это такой вид согласования, при котором главное и зависимое слова обладают одинаковыми категориями (числа и рода, например), и зависимое слово грамматически уподобляется главному. Такой вид согласования наблюдается в бисубстантивных предложени- 
ях со связками в форме прошедшего времени: Берлин показался мне городом подростков, получивших накануне в подарок тесаки и каски, трости и трубки, настояшие велосипеды и сюртуки, как у взросльх (Б. Пастернак); Её мать родилась в далёкой нерусской деревне и не называлась эмигранткой только потому, что и Петербург, и её родина входили в одну империю, и кмоменту рождения матери никто из живых за это уже не отвечал (Е. Чижова); Чувство к Даше не было похоже на те, прежние (А.Н. Толстой).

Согласование в роде становится невозможным при употреблении подлежащего в форме множественного числа. В этом случае связка может согласовываться с подлежащим только в числе: Весь он был некрасивый, нескладныци, волосы его - рыжеватая жёсткая шапка - напоминали волосы куклы, а пальцы сложным устройством походили на малое собрание шахматных фигур (О. Славникова).

Сравнительно редко в бисубстантивных предложениях употребляются связки в форме будущего времени, в таком случае наблюдается согласование связки с подлежащим в числе: После этого я буду как умный и послушный солдат в распоряжении талантливого генерала (А. Куприн); Обешаю, что вы будете первыци её читатель (А. Афанасьев) - эквивалентом существительного в данном предложении является личное местоимение, что позволяет связке согласовываться и в лице.

Смысловое согласование - это разновидность согласования, при котором форма зависимого слова отражает не грамматические категории главного, a реальные признаки обозначенного главным словом предмета (пол чело- века или животного, единичность или множественность и под.). Смысловое согласование в роде наблюдаются в бисубстантивных предложениях при использовании в позиции подлежащего личных местоимений 1 и 2 лица: $\boldsymbol{T} \boldsymbol{b} \boldsymbol{t}$ должен быть похож на него хотя бы издали, иначе чёртовы дикари попрячутся (Б. Акунин); Я был бы последний дурак (А. Грин). Если в функции подлежащего употребляются другие разряды местоимений, которые могут иметь форму рода и числа, в бисубстантивном предложении реализуется собственно согласование: Затем Саня перевернул небольшой странноватьй стул, и тот превратился в невысокую лесенку (Л. Улицкая); Не прошло и месяиа со дня вашей свадьбы, а она уже похожа у вас на щепку! (A. Чехов); Te, кто списывал у неё на экзаменах, преданно дыша в плечо, теперь оказались устроены в газетах, щедро опекаемых властями, и даже превратились в щеголеватых маленьких начальников... (О. Славникова). Смысловое согласование в числе характерно для предложений, в которых подлежащее выражено словосочетанием: Мы с братом были круглье сироты (М. Шолохов); Чуть не треть приходятся нашему капитану родней, остальные соседи или давние приятели (Б. Акунин); Ведь мы с тобой не прохвосты какие-нибудь, а представители именитого купеческого рода (А. Чехов).

Необходимо отметить, что в русском языке существует группа бисубстантивных предложений, в которых связка согласуется не с подлежащим, а с субстантивной частью сказуемого: Но утро - это была Лиза (В. Каверин) - метафорическое употребление собственного имени в позиции именной части связочно-субстантивного 
сказуемого, влияет на согласование связки с этим именем в роде.

Анализ бисубстантивных предложений показывает, что среди них существуют предложения, имеющие формальную возможность для оформления предикативных отношений связью согласование, однако эта возможность не всегда используется. В связи с этим считаем необходимым различать согласованные и несогласованные бисубстантивные предложения. Согласованными считаем БП, в которых материально выраженная связка согласуется в роде, числе или только в числе с подлежащим. Несогласованными называем бисубстантивные предложения, имеющие формальную основу для согласования, заключающуюся в наличии в предложении связки в форме прошедшего или будущего времени, но не имеющие согласования связки с подлежащим. В этих предложениях связка согласуется с субстантивной частью связочно-субстантивного сказуемого.

Кроме названных разновидностей существуют бисубстантивные предложения, в которых отсутствует формальная основа для выражения связи. Это предложения с формами настоящего времени [7] связки былть, как нулевой формой, так и материально выраженной формой есть: Интересньıй вы народ: все хотят за копейку спастись (Ю. Буйда); Пафос Бакунина есть прообраз той могучей силь, с какою выступят на борьбу новые классь (А.Н. Толстой). Предложения, не имеющие формальной возможности для осуществления согласования связки с подлежащим, считаем несогласуемыми. Несогласуемые бисубстантивные предложения составляют значительную группу БП и требуют специального исследования.

\section{ЛИТЕРАТУРА:}

1. Адмони В.Г. Двучленные фразы в трактовке Л.В. Щербы и проблема предикативности // Научн. докл. высш. школы. Филологические науки, 1960, № 1.

2. Востоков В.В. Грамматические значения простого предложения в современном русском языке // Проблемы современной русистики: материалы Всероссийской научно-практической конференции, посвящённой 70-летию доктора филологических наук, профессора В.В. Востокова, 18-20 сентября 2014 г. / отв. ред. С.Н. Пяткин; Арзамасский филиал ННГУ. Арзамас: Арзамасский филиал ННГУ, 2014. С. 37-44.

3. Калинин А.Ф. Формальная и смысловая организация русских фразеологизованных предложений типа Каких только подарков ему не накупили! (структурно-грамматический и логико-семантический аспекты) // Вестник Московского государственного областного университета. Серия: Русская филология. 2013. № 2. М.: Изд-во МГОУ. С. 5-12.

4. Кубик М. Модели двусоставных глагольных предложений русского языка в сопоставлении с чешскими. Praha, 1977.

5. Русская грамматика. М., 1980. T. II. С. 709.

6. Чеснокова Л.Д. Связи слов в современном русском языке. М.: Просвещение, 1980.

7. Шаповалова Т.Е. Субъективная семантика глагольных форм настоящего времени в повести М.Ю. Лермонтова «Максим Максимыч» // Русистика и компаративистика: сб. научн. ст. / гл. ред. М.Б. Лоскутникова. Вып. IX. М.: МГПУ, 2014. С. 61-69. 